\title{
Macroscopic transport by synthetic molecular machines
}

\author{
JOSÉ BERNÁ1, DAVID A. LEIGH'*, MONIKA LUBOMSKA², SANDRA M. MENDOZA², EMILIO M. PÉREZ', \\ PETRA RUDOLF*, GILBERTO TEOBALDI ${ }^{3}$ AND FRANCESCO ZERBETT ${ }^{3 *}$
}

\author{
${ }^{1}$ School of Chemistry, University of Edinburgh, The King's Buildings, West Mains Road, Edinburgh EH9 3JJ, UK \\ ${ }^{2}$ Materials Science Centre, Rijksuniversiteit Groningen, Nijenborgh 4, 9747AG Groningen, The Netherlands \\ ${ }^{3}$ Dipartimento di Chimica 'G. Ciamician', Università degli Studi di Bologna, v. F. Selmi 2, 40126 Bologna, Italy \\ *e-mail: David.Leigh@ed.ac.uk; P.Rudolf@rug.nl; francesco.zerbetto@unibo.it
}

Published online: 28 August 2005; doi:10.1038/nmat1455

Nature uses molecular motors and machines in virtually every significant biological process, but demonstrating that simpler artificial structures operating through the same gross mechanisms can be interfaced with-and perform physical tasks in-the macroscopic world represents a significant hurdle for molecular nanotechnology. Here we describe a wholly synthetic molecular system that converts an external energy source (light) into biased brownian motion to transport a macroscopic cargo and do measurable work. The millimetre-scale directional transport of a liquid on a surface is achieved by using the biased brownian motion of stimuli-responsive rotaxanes ('molecular shuttles') to expose or conceal fluoroalkane residues and thereby modify surface tension. The collective operation of a monolayer of the molecular shuttles is sufficient to power the movement of a microlitre droplet of diiodomethane up a twelve-degree incline.
D iological motors rectify random motion in the molecular Dorld to generate directional force and carry out macroscopic tasks $^{1}$. Indeed, they do this so effectively that they can be capable of transporting objects many times more massive than themselves ${ }^{2}$ and have even been used to power prototypical hybrid mechanical devices ${ }^{3-8}$. However, performing well-defined mechanical tasks and measurable work with synthetic molecular systems that bias brownian motion has proved much more elusive $^{9-13}$. Here we report on the macroscopic (millimetre-scale) directional transport of a droplet on a photo-responsive surface created by using the nanometre displacement of the components of light-switchable molecular shuttles to expose or conceal fluoroalkane residues and thereby modify the surface properties.

Stimuli-responsive molecular shuttles are rotaxanes in which the macrocycle is translocated from one position ('station') on the thread to a second site through biased brownian motion in response to an external trigger (for example, light, electrons, temperature, $\mathrm{pH}$, nature of the environment, reversible covalent bond formation, and so on $)^{9-20}$. These systems are viewed as potential elements for molecular machinery and the change in position of the subunits has been used as a nanoscale mechanical switch to vary physical properties such as conductivity ${ }^{14}$, induced circular dichroism ${ }^{15}$ and fluorescence ${ }^{16-19}$. Using such a stimuli-induced co-conformational change, we envisaged that the macrocycle in a shuttle such as 1 (Fig. 1) could expose or conceal a short fluoroalkane segment (the tetrafluorosuccinamide station) in response ${ }^{20}$ to photoisomerization of the fumaramide station (which has a high binding affinity for the ring) to maleamide (which has a low binding affinity for the ring). As the contact angles of both polar and apolar liquids are highly sensitive to small variations in the concentrations of fluoroalkane groups ${ }^{21}$, it seemed possible that the biased brownian motion associated with an $E-1$ to $Z$-1 transformation could be used to produce a rotaxane-terminated surface with switchable wettability characteristics ${ }^{22}$.

Rotaxane $E$-1 was prepared in $65 \%$ yield from thread $E-2$, then protonated with trifluoroacetic acid to mimic the methodology subsequently used for self-assembled monolayer (SAM) formation 


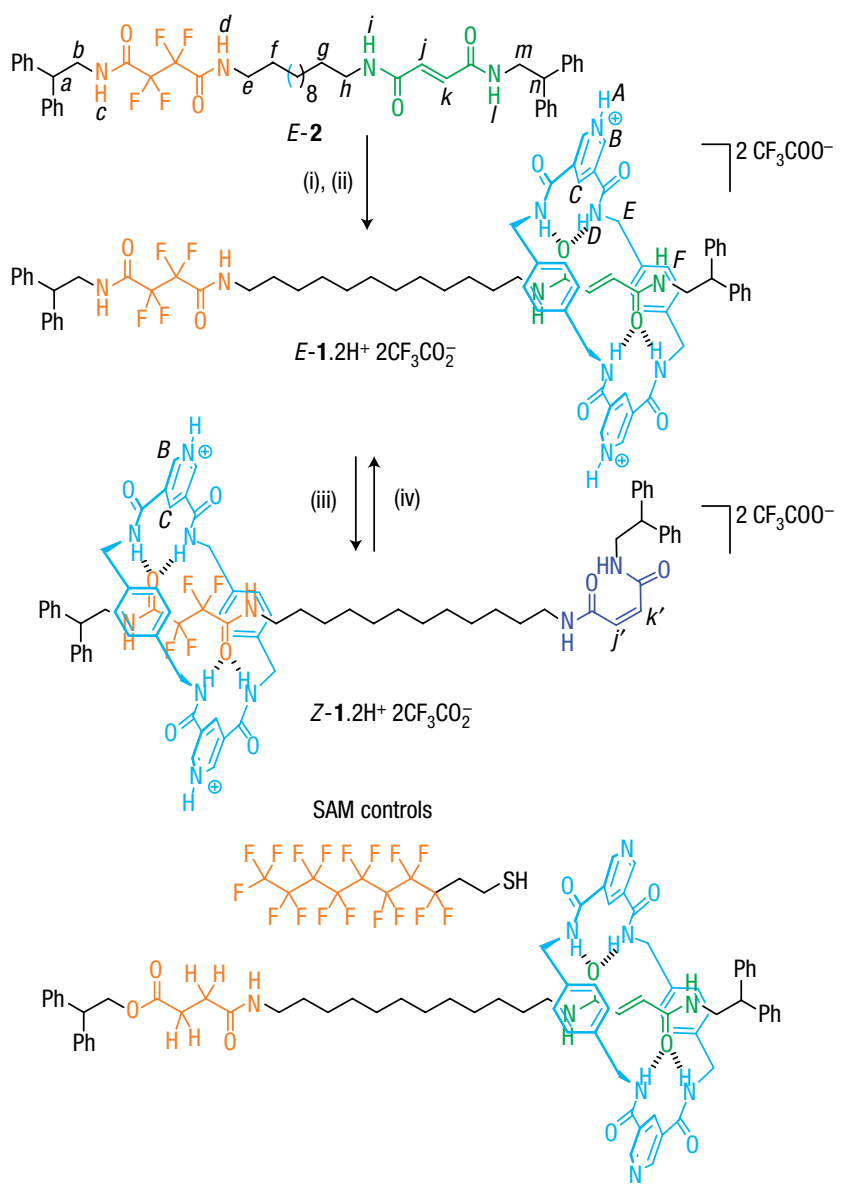

Figure 1 Synthesis and light-induced positional change of the macrocycle in a fluorinated molecular shuttle, 1. Rotaxane $E-1$ contains a fumaramide (green) station and a tetrafluorosuccinamide (orange) station. $E \rightarrow Z$ photo-isomerization of the fumaramide group generates the maleamide (dark blue) station (Z-1), which has a low affinity for the macrocycle. The $E / Z-1$ ratio is $50: 50$ at the photostationary state in $\mathrm{CH}_{2} \mathrm{Cl}_{2}$ at $298 \mathrm{~K}$. Reaction conditions: (i) 10 equiv. 3,5-pyridinedicarbonyl dichloride, 10 equiv. $p$-xylylenediamine, $\mathrm{Et}_{3} \mathrm{~N}, \mathrm{CHCl}_{3}, 65 \%$; (ii) $\mathrm{CF}_{3} \mathrm{CO}_{2} \mathrm{H}, \mathrm{CH}_{2} \mathrm{Cl}_{2}$; (iii) $254 \mathrm{~nm}, \mathrm{CH}_{2} \mathrm{Cl}_{2}, 5 \mathrm{~min}, 50 \%$; (iv) piperidine, $\mathrm{CH}_{2} \mathrm{Cl}_{2}$, RT, $2 \mathrm{~h}$ then $\mathrm{CF}_{3} \mathrm{CO}_{2} \mathrm{H}$, $100 \%$ or $115^{\circ}, \mathrm{C}_{2} \mathrm{H}_{2} \mathrm{Cl}_{4}, 24 \mathrm{~h}, 90 \%$.

and converted into $Z-\mathbf{1}$ by photoisomerization (Fig. 1). The photostationary state of $E / Z-1$ at $254 \mathrm{~nm}$ is $50: 50$ in $\mathrm{CH}_{2} \mathrm{Cl}_{2}$ at room temperature and, starting from either isomer, is reached within 5 min under our experimental conditions with no evidence of any decomposition of the rotaxane or reaction with the solvent. The NMR spectra (Figs 2 and 3) of $E-1$ in $\mathrm{CDCl}_{3}$ confirms the location of the macrocycle over the fumaramide residue in a non-hydrogen-bond-disrupting environment. $\mathrm{H}_{j}$ and $\mathrm{H}_{k}$ are shielded by 1.0 p.p.m. with respect to their position in $E-2$ and no significant shifts are observed for the fluorine resonances between rotaxane and thread. In contrast, the ${ }^{1} \mathrm{H}$ (Fig. 2) and ${ }^{19} \mathrm{~F}$ (Fig. 3) NMR spectra show that in $Z-\mathbf{1}$ the macrocycle resides primarily over the fluoroalkane station. $\mathrm{H}_{j^{\prime}}$ and $\mathrm{H}_{k^{\prime}}$ occur at similar chemical shifts in rotaxane and thread whereas the ${ }^{19} \mathrm{~F}$ nuclei in $Z-1$ are shielded by $\sim 0.7$ p.p.m. by the xylylene groups of the macrocycle (as aromatic ring currents change the local magnetic field by a value independent of the nuclei being observed, the magnitude of the shielding in the ${ }^{19} \mathrm{~F}$ NMR spectrum is similar to that seen $^{20}$ in the ${ }^{1} \mathrm{H}$ NMR spectrum for analogous non-fluorinated

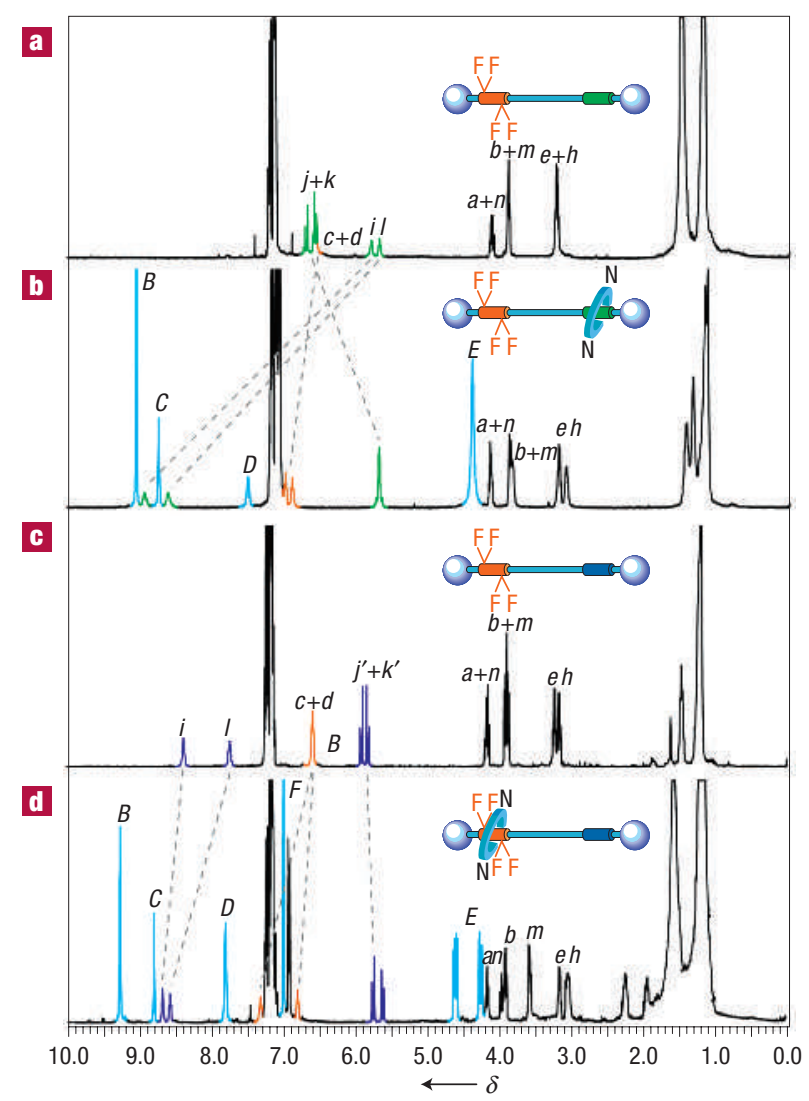

Figure 2 Locating the position of the macrocycle in a molecular shuttle using proton chemical shifts. a-d, ${ }^{1} \mathrm{H}$ NMR spectra $\left(400 \mathrm{MHz}, \mathrm{CDCl}_{3}, 298 \mathrm{~K}\right)$ of a, thread $E-2$, b, [2]rotaxane $E-1, \mathbf{c}$, thread $Z-2$, and $\mathbf{d}$, [2]rotaxane $Z-1$. The shielding of protons in the rotaxanes compared with the threads indicates the position of the macrocycle in each diastereomer.

shuttles). The addition of up to 10 equiv. of $\mathrm{CF}_{3} \mathrm{CO}_{2} \mathrm{H}$ had no effect on the position of the macrocycle in either rotaxane diastereomer. Molecular modelling studies faithfully reproduce the relative positions of the components in both $E$ and $Z$-1 and suggest that both folded and extended chain co-conformers are present.

The macrocycle of the rotaxane contains pyridine groups that have previously been used to graft similar molecular shuttles onto well-ordered SAMs of 11-mercaptoundecanoic acid $\left(\mathrm{HO}_{2} \mathrm{C}\left(\mathrm{CH}_{2}\right)_{10} \mathrm{SH}, 11-\mathrm{MUA}\right)$ on $\mathrm{Au}(111)$ deposited on $\mathrm{SiO}_{2}$ (ref. 23). Using this technique (see Supplementary Information), films were prepared with E-1 using 11-MUA SAMs on $\mathrm{Au}(111)$ deposited on glass or mica (giving E-1.11-MUA.Au(111), Fig. 4). The resulting films were characterized by X-ray photoemission spectroscopy (XPS; X-PROBE Surface Science Laboratories photoelectron spectrometer) and scanning tunnelling microscopy (STM), each confirming that the films featured complete and uniform coverage of the SAM with a monolayer of physisorbed shuttles ${ }^{23}$, with the long axis of the rotaxane thread lying parallel to the gold surface. As controls (Fig. 1), films were prepared using a similar non-fluorinated shuttle (in addition to replacing the fluorine atoms of $\mathbf{1}$ with hydrogens, substitution of the amide group nearest the succinic stopper with an ester group was necessary because the low solubility of the tetra-amide thread hindered rotaxane synthesis) and a simple non-photoactive fluorocarbon, heptadecafluorodecanethiol $\left(\mathrm{CF}_{3}\left(\mathrm{CF}_{2}\right)_{7} \mathrm{CH}_{2} \mathrm{CH}_{2} \mathrm{SH}\right)$. 


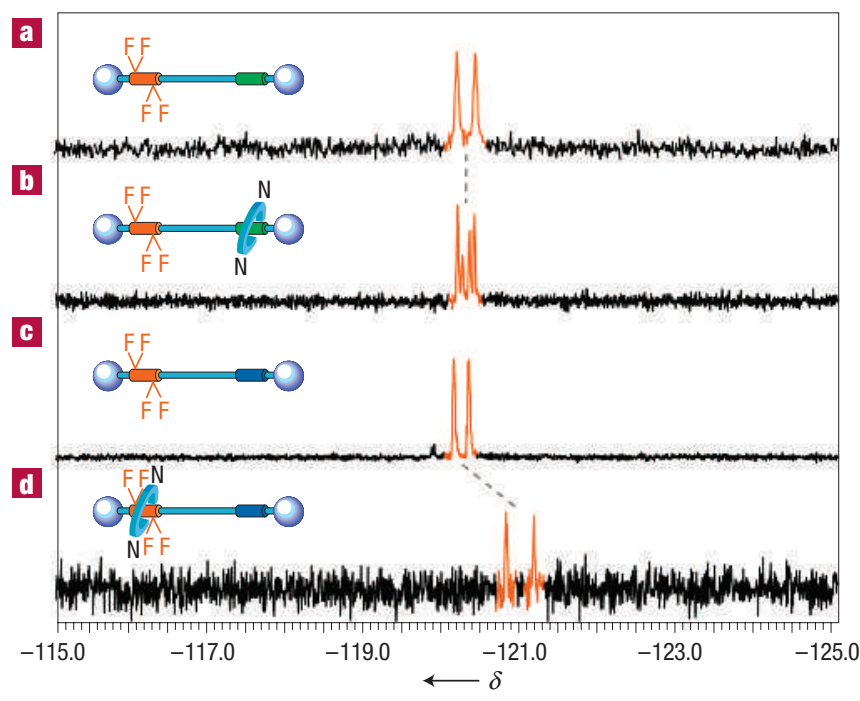

Figure 3 Locating the position of the macrocycle in a molecular shuttle using fluorine chemical shifts. a-d, ${ }^{19} \mathrm{~F} \mathrm{NMR}$ spectra $\left(235 \mathrm{MHz}, \mathrm{CDCl}_{3}, 298 \mathrm{~K}\right)$ of a, thread $E-2, \mathbf{b}$, [2]rotaxane $E-1, \mathbf{c}$, thread $Z-2$, and d, [2]rotaxane $Z-1$. The shielding of the fluorine atoms in $Z-1$ indicates the macrocycle is situated over the fluorocarbon station.

The fluorinated molecular shuttle substrate, E-1.11-MUA.Au (111), did indeed provide a photo-responsive surface (Table 1$)^{24}$. Small $(0.5-5 \mu \mathrm{l})$ drops of several low-volatility liquids (for example, water, formamide $\left(\mathrm{H}_{2} \mathrm{NCHO}\right)$, ethylene glycol and diiodomethane $\left.\left(\mathrm{CH}_{2} \mathrm{I}_{2}\right)\right)$ each gave significantly $\left(8-22^{\circ}\right)$ lower contact angles on surfaces physisorbed with $E$-1 after irradiation for $5 \mathrm{~min}$ with ultraviolet light, providing evidence that positional switching of the macrocycle was occurring on the surface of the SAM (that is, E/Z-1.11-MUA.Au(111), Fig. 4$)^{25-30}$. In contrast, the films with the surfaces terminated with either the non-fluorinated shuttle or heptadecafluorodecanethiol gave contact angles that did not change on irradiation. Lower contact angles for the non-fluorinated shuttle-terminated surface compared with E-1.11-MUA.Au(111), and the invariance of the contact angle to the $E / Z$ ratio using the non-fluorinated system, suggest that the photo-induced lowering of the contact angle in $E / Z$-1.11-MUA.Au(111) is caused by a reduction in the number of fluoroalkane residues exposed at the surface of the substrate, although the partial self-satisfying $\mathrm{H}$-bonding requirements of the maleamide group may also contribute to the increase in the surface energy.

Surface energy heterogeneity ${ }^{31-35}$ brought about by photoinduced wetting/de-wetting has previously ${ }^{36,37}$ been used to move droplets of liquids across surfaces. In a two-stage process, an azobenzene-terminated surface was photoisomerized to cis (wetting the surface) and then asymmetrically irradiated at the rear of the droplet at a second wavelength (cis-to-trans isomerization), selectively de-wetting the back edge of the droplet and pushing it forward. We investigated photo-driven drop transport on E-1.11-MUA.Au(111) using a single irradiation method (see Supplementary Information Videos and Figs 5 and 6).

A $1.25 \mu \mathrm{l}$ drop of diiodomethane, the liquid that shows the most discrimination between the pristine and irradiated surfaces (Table 1), was deposited on a freshly prepared sample of E-1.11-MUA.Au(111) on glass (contact angle $35 \pm 2^{\circ}$, Fig. 5a) and the sample was irradiated with a perpendicular beam of 240-400 $\mathrm{nm}$ light focused on one side of the drop and the
Table 1 Contact angles of $1.25 \mu \mathrm{l}$ droplets of various low-volatility liquids deposited on E-1 grafted onto a 11-MUA SAM on $\mathrm{Au}$ (111) on mica (similar contact angles were obtained using glass). The droplets were deposited before (E-1.11-MUA.Au(111)) and after (E/Z-1.11-MUA.Au(111)) irradiation of the surface with ultraviolet light (240-400 nm) for $5 \mathrm{~min}$. Irradiation for longer periods had no further effect on the contact angles. X-ray photoemission spectroscopy (XPS) measurements indicate identical elemental composition before and after irradiation. Drops were deposited on the ultraviolet-irradiated surface immediately after the light was switched off. Olive oil, $m$-xylene, 1-methylnaphthalene, 1,1,2,2-tetrachloroethane, 1,1,2-tribromoethane, chlorobenzene, perfluorohexane, 1,4-dioxane, tetrachloromethane and tetradecane all fully wet the E-1.11-MUA.Au(111) surface rather than form droplets.

\begin{tabular}{|c|c|c|}
\hline & \multicolumn{2}{|c|}{$\theta\left({ }^{\circ}\right)^{*}$} \\
\hline & $\begin{array}{l}\text { Deposited before } \\
\text { ultraviolet irradiation } \\
\text { of surface }\end{array}$ & $\begin{array}{l}\text { Deposited after } \\
\text { ultraviolet irradiation } \\
\text { of surface }\end{array}$ \\
\hline Diiodomethane & 35 & 13 \\
\hline Water & 55 & 45 \\
\hline Formamide & 40 & 31 \\
\hline Ethylene glycol & 48 & 40 \\
\hline Bromoform & 18 & 12 \\
\hline Dimethylformamide & 15 & $-\ddagger$ \\
\hline Nitromethane & $6^{\dagger}$ & $5^{\dagger}$ \\
\hline 1,2-dibromoethane & 8 & $-\ddagger$ \\
\hline \multicolumn{3}{|c|}{${ }^{*}$ Measured 30 and $60 \mathrm{~s}$ after deposition. Experimental error $\pm 2^{\circ}$. } \\
\hline \multicolumn{3}{|c|}{$\dagger$ Significant evaporation after 2.5 min. } \\
\hline \multicolumn{3}{|l|}{$\ddagger$ Fully wets surface. } \\
\hline
\end{tabular}

adjacent area to produce a gradient in the surface free energy across the length of the drop. After irradiation for $80 \mathrm{~s}$ the front of the drop started to advance at a dynamic contact angle of $30 \pm 2^{\circ}$ (see the 'Droplet on flat 1.11-MUA.Au(111).glass' video in the Supplementary Information), which continued to decrease during the wetting of the surface. The advancing contact angle remained at least $1^{\circ}$ lower than the receding contact angle during this initial extension period, the inequality of contact angles illustrating the difference in surface properties caused by the irradiation. If irradiation was stopped at any point, no further changes to the droplet were observed until irradiation was re-started. After a total of $900 \mathrm{~s}$ irradiation time (Fig. 5b), the droplet had elongated by $0.8 \mathrm{~mm}$ and the advancing dynamic contact angle decreased to $13 \pm 2^{\circ}$. From 900 to $1,010 \mathrm{~s}$ transport of the entire droplet occurred at a mean speed of $\sim 1 \mu \mathrm{m} \mathrm{s}^{-1}$, during which time the contact angles on the illuminated and the nonilluminated side of the drop were essentially equivalent (Fig. 5c). By $1,110 \mathrm{~s}$ (Fig. 5d), the contact angle had reduced to its minimum value of $12 \pm 2^{\circ}$ and irradiation produced no further changes until evaporation became significant.

At a simple level, the mechanism of drop transport seems straightforward: as the right-hand side (as shown in Fig. 5a) of the drop and adjacent section of the surface is irradiated with ultraviolet light, the $E / Z$ ratio of shuttles on that part of the surface starts to decrease and that part of the surface becomes less polarophobic. The contact angle at the right-hand side of the drop decreases, causing a Laplace pressure gradient inside the droplet ${ }^{38,39}$, and the forward edge creeps along the surface, elongating the droplet and wetting the surface. As the $E / Z$ ratio on the irradiated region of the surface progressively decreases, the droplet spreads further along the surface. A necessary consequence of the forward movement of the front edge of the droplet is that the back edge of the droplet is forced to make a thermodynamic contact angle with the unchanged polarophobic surface that is shallower than the original preferred angle. Consequently, at a critical point the original position of the rear end of the droplet becomes so 


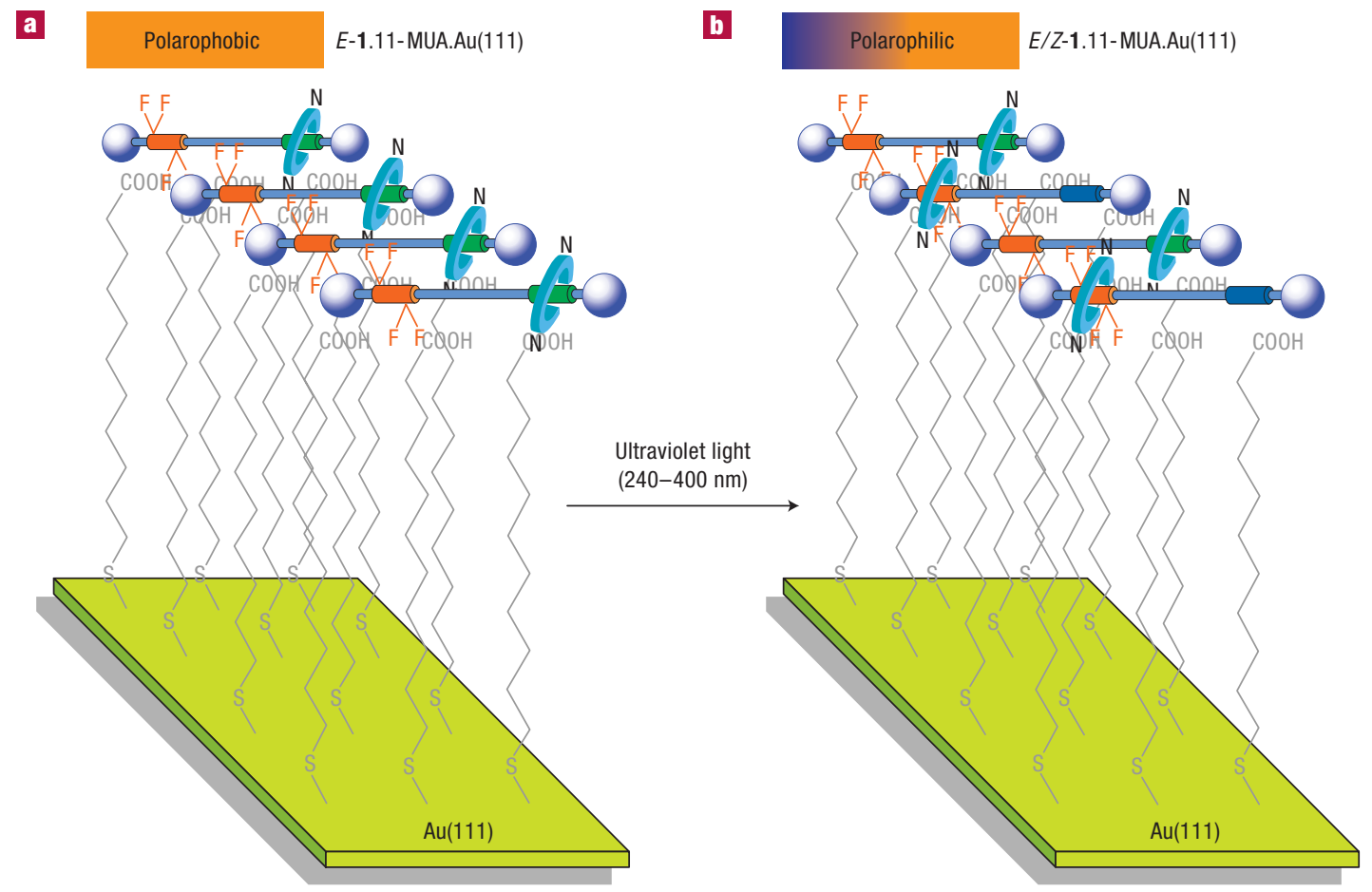

Figure 4 A photo-responsive surface based on switchable fluorinated molecular shuttles. a, Light-switchable rotaxanes with the fluoroalkane region (orange) exposed (E-1) were physisorbed onto a SAM of 11-MUA on Au(111) deposited on either glass or mica to create a polarophobic surface, E-1.11-MUA.Au(111). b, Illumination with 240-400 nm light isomerizes some of the $E$ olefins to $Z$ (giving a 50:50 ratio at the photostationary state if the reaction on the surface mirrors that in solution), causing a nanometre displacement of the rotaxane threads in the Z-shuttles which encapsulates the fluoroalkane units leaving a more polarophilic surface, $E / Z-1.11-\mathrm{MUA}$.Au(111). Photoemission spectroscopy data are consistent with the molecular shuttles lying parallel to the Au surface (but they are not directionally aligned or necessarily linear as depicted for clarity in this cartoon).

energetically unfavourable that the progressive driving force for increasing wetting at the front end of the drop causes contraction of the droplet from the rear to occur, leading to sudden and reasonably rapid transport of the droplet towards the low $E / Z$ ratio region of the surface. Further irradiation only slightly reduces the contact angle until a photostationary state is reached. Transport was not observed on E-1.11-MUA.Au(111) using $1.25 \mu$ l droplets of water or formamide and the movement of significantly larger $(>2.5 \mu \mathrm{l})$ droplets of $\mathrm{CH}_{2} \mathrm{I}_{2}$ was slower, suggesting that transport does not occur when the gradient of the surface free energy arising from irradiation is low compared with the adhesion, surface tension and viscosity of the droplet ${ }^{37,40}$.

The E-1.11-MUA.Au(111) surfaces are stable and can be used repeatedly for contact angle measurements and transport experiments with the same results over the course of several weeks. In contrast, diiodomethane droplets on SAMs made from the control non-fluorinated shuttle or other shuttles ${ }^{23}$ or heptadecafluorodecanethiol did not undergo contact angle change or transportation even after 20 min ultraviolet irradiation. Nevertheless, we investigated whether other (photo)chemistry of $E$ - or $Z-1$ and $\mathrm{CH}_{2} \mathrm{I}_{2}$, rather than just photoisomerization and shuttling of the fluorinated rotaxane, might be contributing to the observed effects. (i) Neither $E$ - or Z-1 showed any trace of alkylation of the pyridine groups when dissolved in a 1:1 mixture of $\mathrm{CH}_{2} \mathrm{I}_{2} / \mathrm{CH}_{2} \mathrm{Cl}_{2}$ (the rotaxanes are not soluble in neat $\mathrm{CH}_{2} \mathrm{I}_{2}$ ) at room temperature for $24 \mathrm{~h}$. (ii) The iodine atoms of $\mathrm{CH}_{2} \mathrm{I}_{2}$ do not act as a 'heavy atom' triplet sensitizer for the olefin in $E-1$; the rate of isomerization and the $E / Z$ ratio in the photostationary state is the same in $\mathrm{CH}_{2} \mathrm{I}_{2} / \mathrm{CH}_{2} \mathrm{Cl}_{2}$ solution as it is in $\mathrm{CH}_{2} \mathrm{Cl}_{2}$. (iii) $\mathrm{X}$-ray photoemission spectroscopy (XPS) reveals no damage or change in elemental composition after $10 \mathrm{~min}$ ultraviolet irradiation of the E-1.11-MUA.Au(111) surface and also shows that the shuttle is intact on the surface after the droplet transport. (iv) Although the photo-induced cyclopropanation of electron-rich olefins with $\mathrm{CH}_{2} \mathrm{I}_{2}$ is known to occur over 2-60 h using strong ultraviolet sources ${ }^{41-43}$, the olefin in $E-\mathbf{1}$ is electron poor and no degradation, side product or reaction of $E-\mathbf{1}$ besides isomerization was observed when the solution photo-isomerization experiment (254 or $312 \mathrm{~nm}$ ) was carried out for $20 \mathrm{~min}(4 \times$ longer than normal) in $\mathrm{CH}_{2} \mathrm{I}_{2} / \mathrm{CH}_{2} \mathrm{Cl}_{2}$. No discolouration of $\mathrm{CH}_{2} \mathrm{I}_{2}$ was observed (indicative of the formation of $\mathrm{I}_{2}$ ) either in solution or in the liquid droplet experiments. (v) Finally, we note that the contact angle of the droplet in Fig. 5b-d (that is, just before and after transport) is similar to that of a non-irradiated $\mathrm{CH}_{2} \mathrm{I}_{2}$ droplet deposited on the irradiated surface (see Table 1), suggesting that any photochemistry of $\mathrm{CH}_{2} \mathrm{I}_{2}$ (ref. 44) during the experiment does not significantly effect the fluorophobicity of the droplet. However, we cannot rule out that it may play some role in altering the viscosity, surface tension or interaction with the monolayer.

Mica provides a flatter and more regular surface than glass and consequently SAMs are generally more ordered using $\mathrm{Au}(111)$ deposited on mica. We found that although the contact angles were the same for the SAMs on the different substrates the transport of $\mathrm{CH}_{2} \mathrm{I}_{2}$ was significantly more facile using mica (Fig. 6 and the Supplementary Information for the 'Droplet on flat 1.11-MUA.Au(111).mica' video; and the '0.6 Microlitre droplet on 


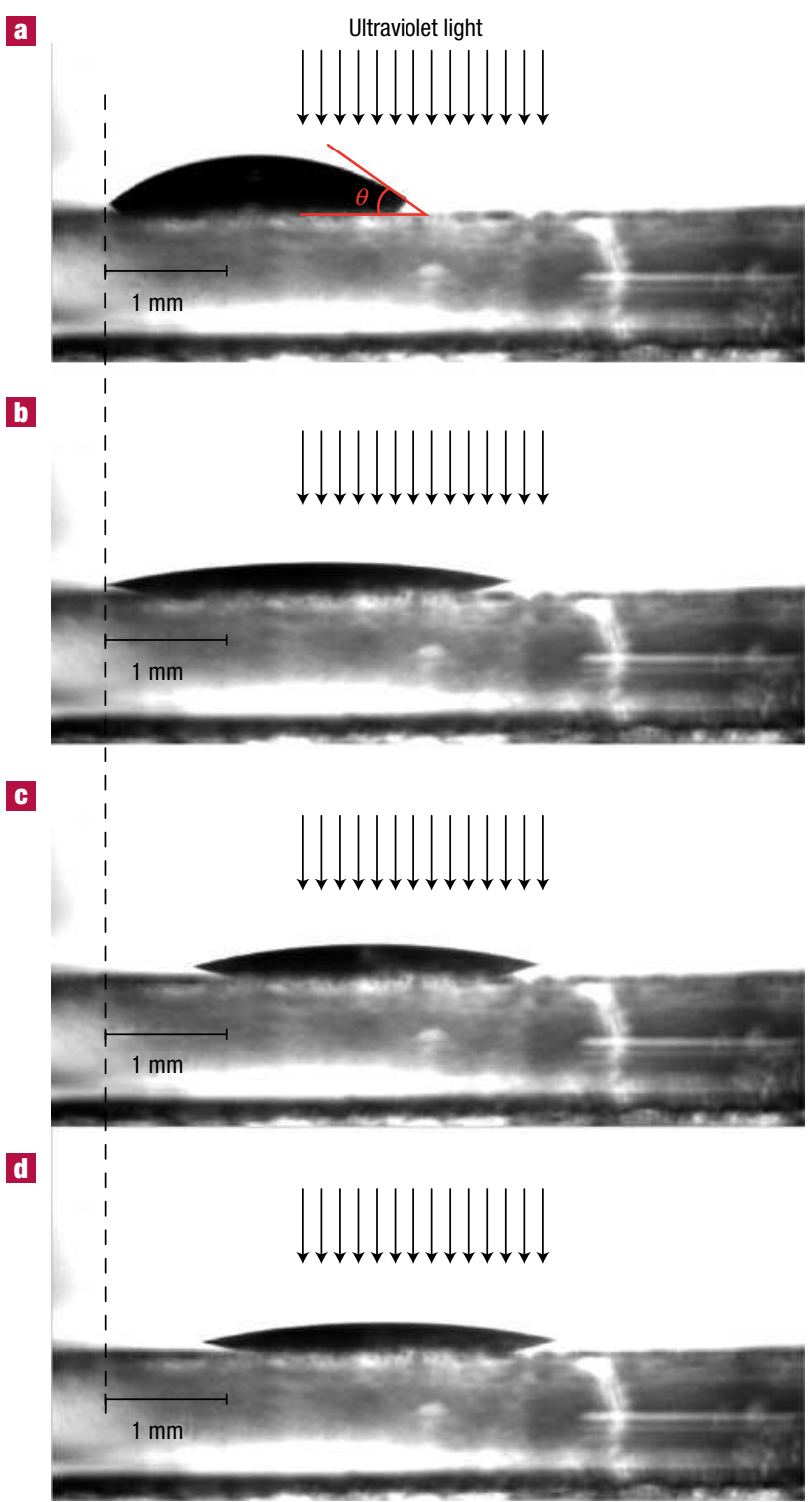

Figure 5 Lateral photographs of light-driven directional transport of a $1.25 \mu \mathrm{l}$ diiodomethane drop across the surface of a E-1.11-MUA.Au(111) substrate on glass. The direction of transportation was controlled by irradiation with a perpendicular beam of 240-400 nm light focused on one side of the drop and the adjacent surface. The irradiation time required for transport and the distance the droplet travels depends on the precise position of the lamp. a, Before irradiation (pristine $E-1.11-\mathrm{MUA} . A u(111)$ ), contact angle $35 \pm 2^{\circ}$. Immediately after this image was taken, the ultraviolet light beam positioned as indicated was switched on. b. After $900 \mathrm{~s}$ of irradiation, contact angle $13 \pm 2^{\circ}$ (illuminated side), $15 \pm 2^{\circ}$ (non-illuminated side). The diiodomethane drop has spread from the high $E / Z-1$ ratio area in the direction of the low $E / Z-1$ ratio region, increasing the total wetted area, and is about to be transported. c, After $1,010 \mathrm{~s}$ of irradiation (just after transport), contact angle $13 \pm 2^{\circ}$. d, After $1,110 \mathrm{~s}$ of irradiation (at the photostationary state), contact angle $12 \pm 2^{\circ}$. Evaporation of the $1.25 \mu \mathrm{l}$ drop of diiodomethane becomes significant after about $1 \mathrm{~h}$. (See the 'Droplet on flat 1.11-MUA.Au(111).glass' video available as Supplementary Information.)

flat 1.11-MUA.AU(111).mica' video for the movement of a smaller droplet). Indeed, the rear end of the droplet could be transported more than $1.5 \mathrm{~mm}$ (compared with $0.8 \mathrm{~mm}$ using $\mathrm{Au}(111)$ on glass, Fig. 5) on the new photo-responsive surface (Fig. 6d).

\section{a
b}
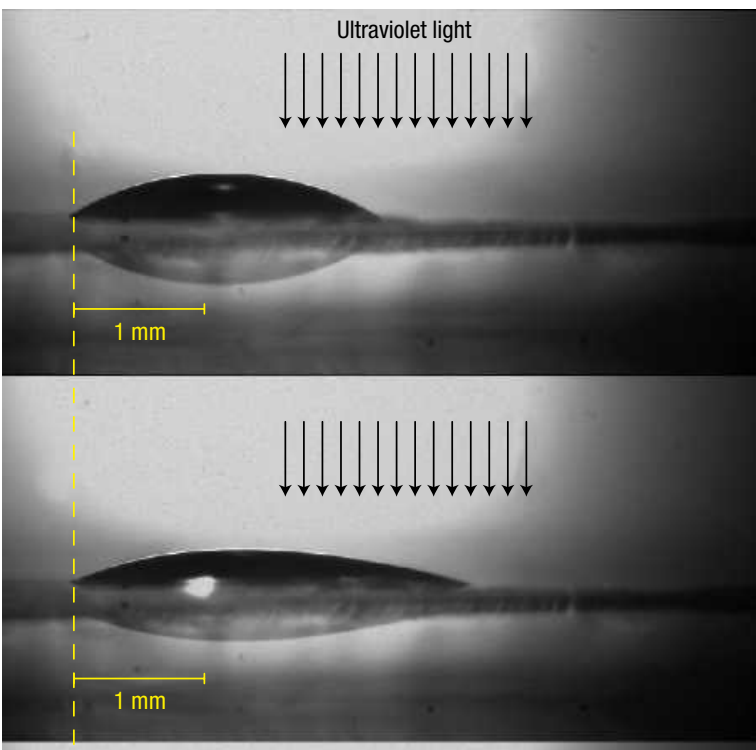

G

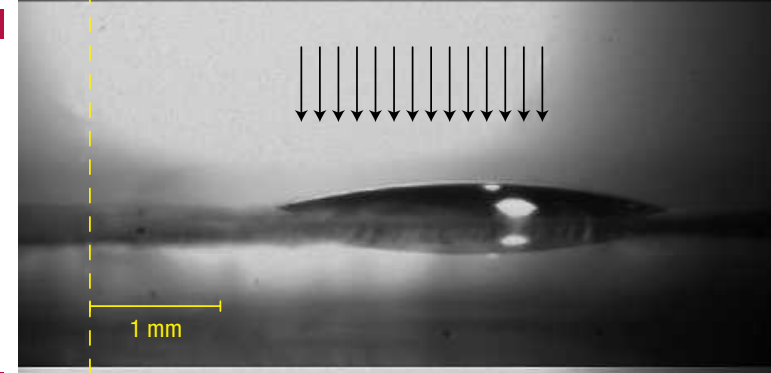

d

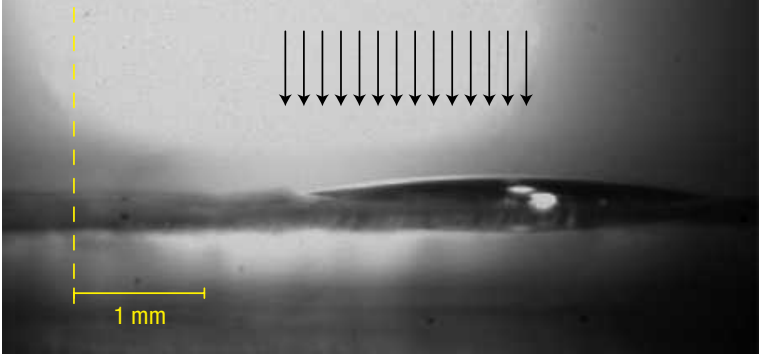

Figure 6 Lateral photographs of light-driven directional transport of a $1.25 \mu \mathrm{I}$ diiodomethane drop across the surface of a E-1.11-MUA.Au(111) substrate on mica. a, Before irradiation (pristine $E-1)$. b, After $215 \mathrm{~s}$ of irradiation ( $20 \mathrm{~s}$ before transport). c, After $370 \mathrm{~s}$ of irradiation (just after transport). d, After $580 \mathrm{~s}$ of irradiation (at the photostationary state). (See the 'Droplet on flat

1.11-MUA.Au(111).mica' video and the related ' 0.6 Microlitre droplet on flat 1.11-MUA.Au(111).mica' video, both available as Supplementary Information.)

Finally, we investigated the ability of the monolayer of molecular shuttles to do macroscopic work against gravity by driving a droplet up a $12^{\circ}$ incline using E-1.11-MUA.Au(111) on mica (Fig. 7 and the 'Droplet uphill 12 degree 1.11MUA.Au(111).mica' video in the Supplementary Information $)^{45}$.

The capillary length, $\kappa^{-1}=\sqrt{\gamma / \rho g}$ (where $\gamma$ is the surface tension of the liquid, $\rho$ is its density, and $g$ is gravity), above which gravity effects should appear is $1.25 \mathrm{~mm}$ for $\mathrm{CH}_{2} \mathrm{I}_{2}$ and the influence of gravity is clearly seen in the Fig. 7 photographs (for example, the directional wetting of the surface and downhill movement of the droplet between Fig. 7c and d). However, even moving uphill, photo-induced wetting and subsequent transport using E-1.11-MUA.Au(111) on mica proved much more 


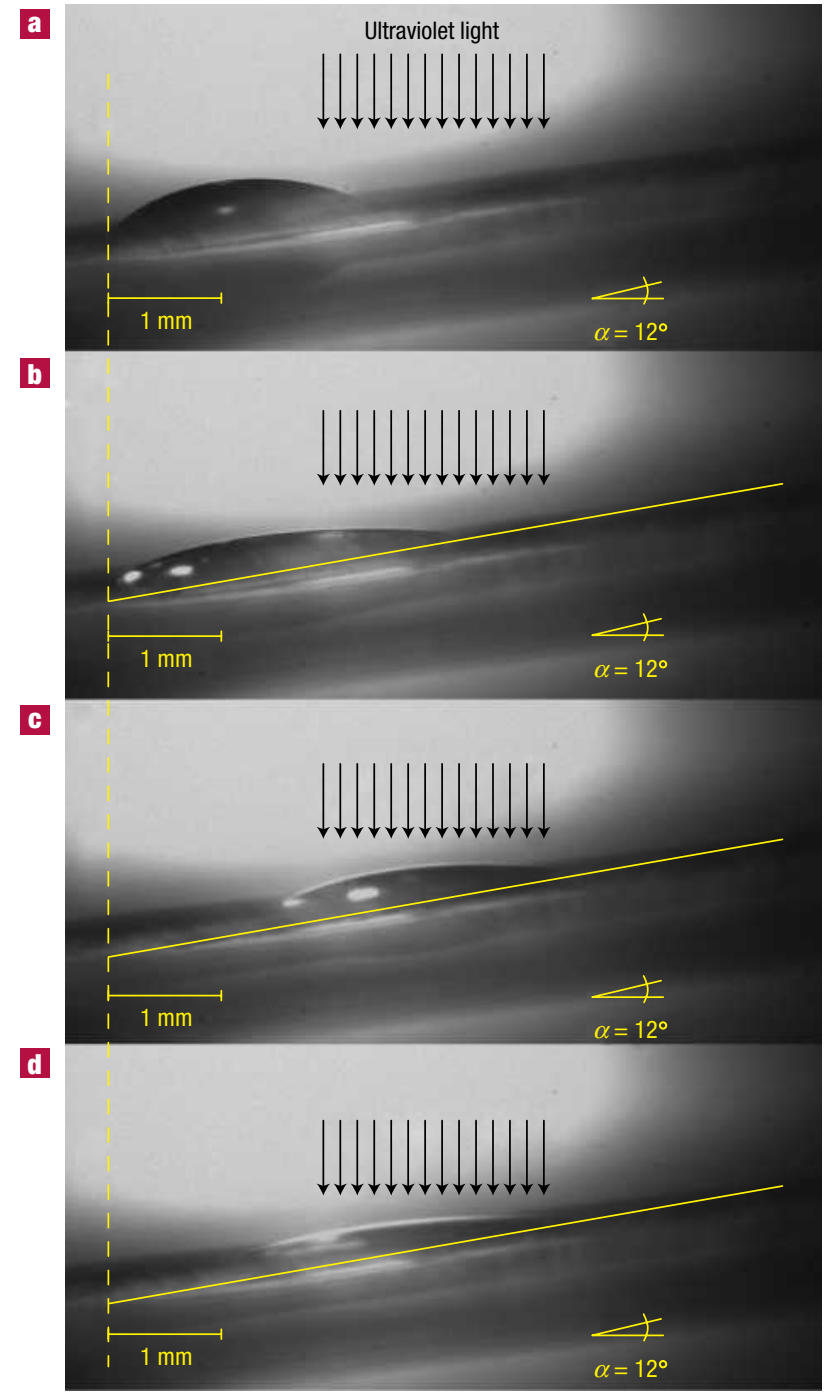

Figure 7 Lateral photographs of light-driven transport of a $1.25 \mu \mathrm{l}$ diiodomethane drop on a E-1.11-MUA.Au(111) substrate on mica up a $12^{\circ}$ incline. For clarity, on photographs $\mathbf{b}-\mathbf{d}$ a yellow line is used to indicate the surface of the substrate. a, Before irradiation (pristine $E-\mathbf{1}$ ). $\mathbf{b}$, After $160 \mathrm{~s}$ of irradiation (just before transport). c, After $245 \mathrm{~s}$ of irradiation (just after transport). d, After $640 \mathrm{~s}$ irradiation (at the photostationary state). Note how the drop moves slightly back downhill under the effect of gravity from $\mathbf{c}$ to $\mathbf{d}$ as the $E / Z$ ratio of the lower part of the incline decreases and the droplet progressively wets more of the surface down the slope. Our experimental set-up does not permit accurate contact-angle measurements on an incline. (See the 'Droplet uphill 12 degree

1.11-MUA.Au(111).mica' video, available as Supplementary Information.)

rapid than on glass. Between 160 and $245 \mathrm{~s}$, the $1.25 \mu \mathrm{l}$ of $\mathrm{CH}_{2} \mathrm{I}_{2}\left(\rho=3.325 \mathrm{~g} \mathrm{ml}^{-1}\right)$ moves $1.38 \mathrm{~mm}$ (at $\sim 16 \mu \mathrm{m} \mathrm{s}^{-1}$ ) up the $12^{\circ}$ incline with no significant change in droplet shape or contact angle. The work done against gravity by the collective action of the monolayer of molecular machines is thus $\left(1.25 \times 10^{-9} \mathrm{~m}^{3} \times 3.325 \times 10^{3} \mathrm{~kg} \mathrm{~m}^{-3}\right)($ mass in $\mathrm{kg}) \times(1.38 \times$ $\left.10^{-3} \mathrm{~m} \times 0.21\left(\sin 12^{\circ}\right)\right)($ height in metres $) \times\left(9.8 \mathrm{~m} \mathrm{~s}^{-2}\right)($ gravity $)=$ $1.2 \times 10^{-8} \mathrm{~J}$. The molecular shuttles each occupy an area of $\sim 3 \mathrm{~nm}^{2}$, so $\sim 2 \times 10^{12}$ molecules are under the elongated drop just before transport. Therefore, if around $40 \%$ of the shuttles have been isomerized by the time the droplet is transported uphill, each molecular machine's contribution to the collective work against gravity-energy stored as potential energy by their action-is $\sim 1.5 \times 10^{-20} \mathrm{~J}$, that is $\sim 9 \mathrm{~kJ} \mathrm{~mol}^{-1}$. Extra work, lost as heat, also has to be done to overcome the viscous forces that resist transport of the droplet. The NMR experiments (Figs 2 and 3) and studies on related rotaxane ${ }^{20}$ indicate that the energy available to do work through the macrocycle in E-1 hydrogen bonding to the fumaramide station rather than the fluoroalkane group is of the order $15-18 \mathrm{~kJ} \mathrm{~mol}^{-1}$. So even if the $12^{\circ}$ slope is the maximum they can overcome (we have yet to determine this), the efficiency of the molecular machines in elevating a droplet by biased brownian motion to store potential energy is at least $50 \%$ of the total free energy made available by the nanometre movements of the individual machine parts.

The extrapolation across the length scales from mechanical motion at the molecular level to macroscopic transport is considerable. However, the mechanism by which it occurs is not a continuous mechanical process. Light fuels chemical reactions, which cause nanometre positional changes in individual molecules by biased brownian motion, which collectively cause a change in the physical properties of the surface, ultimately leading to transport of an object on a length scale a million times larger than the initial change in molecular co-conformation. In doing so, the rotaxane molecules are not individually well described as 'motors'. In both olefin diastereomers of $\mathbf{1}$ the macrocycle is in equilibrium between the binding sites at either end of the thread, the light-fuelled chemical reaction simply changes the position of this equilibrium. If the thread is converted back to its original structure (Fig. 1) the net change in position of the macrocycle is undone, that is $\mathbf{1}$ acts a mechanical switch not a motor. (A key difference between a 'switch' and a 'motor' is that the former is simply a function of state. The property of the system it is influencing does not depend on the trajectory of how the system evolved, merely on what the current state of the switch is.) However, the collective action of the monolayer of molecular mechanical switches does act as a motor, transporting the diiodomethane droplet to a position that it did not sample previously through brownian motion.

The physics of scale means that the transport of small volumes of liquids cannot be achieved using mechanisms based on scaled-down macroscopic pumps ${ }^{32-34}$. Liquid transportation using photo-responsive surfaces may prove useful for delivering analytes in lab-on-a-chip environments, or for performing chemical reactions on a tiny scale without reaction vessels ${ }^{37}$ by bringing individual drops containing different reactants together.

\section{METHODS}

Grafting of the rotaxanes onto the carboxylic acid-terminated SAMs (see Supplementary Information) was achieved by immersing the substrates in a $0.5 \mathrm{mM}$ dichloromethane solution for 6 days. The grafted samples were rinsed three times in pure dichloromethane and dried under argon before the contact-angle measurements. The contact-angle measurements were carried out at room temperature $\left(21{ }^{\circ} \mathrm{C}\right)$ by the sessile drop method, using a custom-built microscope-goniometer system. A $1.25 u 1$ drop of the liquid was placed on a freshly prepared sample using a Hamilton micro-syringe and the drop of the liquid was placed on a freshly prepared sample using a Hamilton micro-syringe and the
contact angle was measured after 30 and $60 \mathrm{~s}$. The samples were irradiated with a perpendicular beam of 240-400 nm light focused on one side of the drop and the adjacent surface and photographs were taken every four (Fig. 5) or five (Figs 6 and 7) seconds. As well as providing the stills shown in the figures, these photographs form the basis of the videos supplied as Supplementary Information. The photo-irradiation experiments on the rotaxane-terminated surfaces were carried out using 240-400 nm light emitted by a $300 \mathrm{~W}$ Xe lamp (Thermo Oriel, Model 66902) using a combination of Thermo Oriel glass filters, 57396 and 51650 . The beam was focused on the sample using Thermo Oriel 77376 fibres positioned $1 \mathrm{~cm}$ above the substrate. Light intensity was measured using a $2 \mathrm{~W}$ broadband power/energy meter, $13 \mathrm{PEM} 001 / \mathrm{J}$ Mellers Griot. The intensity of the ultraviolet light measured $1 \mathrm{~cm}$ from the optical fibres was $2.9 \mathrm{~mW}$. The photo-isomerization experiments in solution were carried out at $254 \mathrm{~nm}$ using a multilamp photo-reactor (Model MLU18, Model 3022 lamps, Photochemical Reactors, Reading, UK).

Received 12 April 2005; accepted 11 July 2005; published 28 August 2005.

References

1. Schliwa, M. (ed.) Molecular Motors (Wiley-VCH, Weinheim, 2003).

2. Noji, H., Yasuda, R., Yoshida, M. \& Kinosita, K. Jr. Direct observation of the rotation of $\mathrm{F}_{1}$-ATPase. Nature 386, 299-302 (1997).

Soong, R. K., Bachand, G. D., Neves, H. P., Olkhovets, A. G. \& Montemagno, C. D. Powering an inorganic nanodevice with a biomolecular motor. Science 290, 1555-1558 (2000).

4. Soong, R. K., Neves, H. P., Schmidt, J. J. \& Montemagno, C. D. Engineering issues in the fabrication of a hybrid nano-propeller system powered by $\mathrm{F}_{1}$-ATPase. Biomed. Microdev. 3, 71-73(2001). 
5. Hess, H., Clemmens, J., Qin, D., Howard, J. \& Vogel, V. Light-controlled molecular shuttles made from motor proteins carrying cargo on engineered surfaces. Nano Lett. 1, 235-239 (2001).

6. Liu, H. et al. Control of a biomolecular motor-powered nanodevice with an engineered chemical switch. Nature Mater. 1, 173-177 (2002).

7. Diez, S. et al. Stretching and transporting DNA molecules using motor proteins. Nano Lett. 3 , 1251-1254 (2003)

8. Hess, H., Bachand, G. D. \& Vogel, V. Powering nanodevices with biomolecular motors. Chem. Eur. J. 10, 2110-2116 (2004)

9. Sauvage, J. P. \& Dietrich-Buchecker, C. (eds) Molecular Catenanes, Rotaxanes and Knots: A Journey Through the World of Molecular Topology (Wiley-VCH, Weinheim, 1999).

10. Balzani, V., Credi, A., Raymo, F. M. \& Stoddart, J. F. Artificial molecular machines. Angew. Chem. Int Edn Engl. 39, 3348-3391 (2000).

11. Balzani, V., Venturi, M. \& Credi, A. Molecular Devices and Machines - A Journey into the Nanoworld (Wiley-VCH, Weinheim, 2003).

12. Kay, E. R. \& Leigh, D. A. Synthetic molecular machines. in Functional Artificial Receptors (eds Schrader, T. \& Hamilton, A. D.) (Wiley-VCH, Weinheim, 2005).

13. Huang, T. J. et al. A nanomechanical device based on linear molecular motors. Appl. Phys. Lett. 85 5391-5393 (2004)

14. Flood, A. H. et al. Meccano on the nanoscale - A blueprint for making some of the world's tiniest machines. Aust. J. Chem. 57, 301-322 (2004).

15. Bottari, G., Leigh, D. A. \& Pérez, E. M. Chiroptical switching in a bistable molecular shuttle. J. Am. Chem. Soc. 125, 13360-13361 (2003).

16. Wang, Q. -C., Qu, D. -H., Ren, J., Chen, K. \& Tian, H. A lockable light-driven molecular shuttle with a fluorescent signal. Angew. Chem. Int. Edn Engl. 43, 2661-2665 (2004).

17. Qu, D. -H., Wang, Q. -C., Ren, J. \& Tian, H. A light-driven rotaxane molecular shuttle with dual fluorescence addresses. Org. Lett. 6, 2085-2088 (2004).

18. Pérez, E. M., Dryden, D. T. F., Leigh, D. A., Teobaldi, G. \& Zerbetto, F. A generic basis for some simple light-operated mechanical molecular machines. J. Am. Chem. Soc. 126, 12210-12211 (2004).

19. Leigh, D. A. et al. Patterning through controlled submolecular motion: Rotaxane-based switches and logic gates that function in solution and polymer films. Angew. Chem. Int. Edn Engl. 44, 3062-3067 (2005).

20. Altieri, A. et al. Remarkable positional discrimination in bistable light- and heat-switchable hydrogen-bonded molecular shuttles. Angew. Chem. Int. Edn Engl. 42, 2296-2300 (2003).

21. Masaaki, Y. \& Masashi, M. Newest Aspects of Fluoro Functional Materials (CMC, Tokyo, 1994).

22. Cavallini, M. et al. Information storage using supramolecular surface patterns. Science 299, 531 (2003).

23. Cecchet, F. et al. Structural, electrochemical, and photophysical properties of a molecular shuttle attached to an acid-terminated self-assembled monolayer. J. Phys. Chem. B 108, 15192-15199 (2004)

24. Katz, E. Lioubashevsky, O. \& Willner I. Electromechanics of a redox-active rotaxane in a monolayer assembly on an electrode. J. Am. Chem. Soc. 126, 15520-15532 (2004).

25. Kim, K. et al. A pseudorotaxane on gold: Formation of self-assembled monolayers, reversible dethreading and rethreading of the ring, and ion-gating behavior. Angew. Chem. Int. Edn Engl. 42 , 2293-2296 (2003).

26. Long, B., Nikitin, K. \& Fitzmaurice, D. Assembly of an electronically switchable rotaxane on the surface of a titanium dioxide nanoparticle. J. Am. Chem. Soc. 125, 15490-15498 (2003).

27. Katz, E., Sheeney Haj, I. \& Willner, I. Electrical contacting of glucose oxidase in a redox-active rotaxane configuration. Angew. Chem. Int. Edn Engl. 43, 3292-3300 (2004).

28. Huang, T. J. et al. Mechanical shuttling of linear motor-molecules in condensed phases on solid substrates. Nano Lett. 4, 2065-2071 (2004).
29. Tseng, H. -R., Wu, D., Fang, N. X., Zhang, X. \& Stoddart, J. F. The metastability of an electrochemically controlled nanoscale machine on gold surfaces. Chem. Phys. Chem. 5, 111-116 (2004).

30. Jang, S. S. et al. Structures and properties of self-assembled monolayers of bistable [2] rotaxanes on $\mathrm{Au}$ (111) surfaces from molecular dynamics simulations validated with experiment. J. Am. Chem. Soc. 127, 1563-1575 (2005)

31. Liu, Y., Mu, L., Liu, B. \& Kong, J. Controlled switchable surfaces. Chem. Eur. J. 11, 2622-2631 (2005).

32. Grunze, M. Driven liquids. Science 283, 41-42 (1999).

33. Gau, H., Herminghaus, S., Lenz, P. \& Lipowsky, R. Liquid morphologies on structured surfaces: from microchannels to microchips. Science 283, 46-49 (1999).

34. Gallardo, B. S. et al. Electrochemical principles for active control of liquids on submillimeter scales. Science 283, 57-61 (1999).

35. Daniel, S., Chaudhury, M. K. \& Chen, J. C. Fast drop movements resulting from the phase change on a gradient surface. Science 291, 633-636 (2001)

36. Ichimura, K., Oh, S. -K. \& Nakagawa, M. Light-driven motion of liquids on a photoresponsive surface. Science 288, 1624-1626 (2000).

37. Oh, S. -K., Nakagawa, M. \& Ichimura, K. Photocontrol of liquid motion on an azobenzene monolayer. J. Mater. Chem. 12, 2262-2269 (2002).

38. Greenspan, H. P. On the motion of a small viscous droplet that wets a surface. J. Fluid Mech. 84, 125-143 (1978).

39. Brochard, F. Motions of droplets on solid surfaces induced by chemical or thermal gradients. Langmuir 5, 432-438 (1989).

40. Neumann, A. W. \& Good, R. J. in Surface and Colloid Science Vol. 11 (eds Good, R. J. \& Stromberg R. R.) 31-91 (Plenum, New York, 1979).

41. Blomstrom, D. C., Herbig, K. \& Simmons, H. E. Photolysis of methylene iodide in the presence of olefins. J. Org. Chem. 30, 959-964 (1965).

42. Pienta, N. J. \& Kropp, P. J. Photochemistry of alkyl halides. 6. gem-Diiodides. A convenient method for the cyclopropanation of olefins. J. Am. Chem. Soc. 100, 655-657 (1978).

43. Kropp, P. J., Pienta, N. J., Sawyer, J. A. \& Polniaszek, R. P. Photochemistry of alkyl halides-VII Cyclopropanation of alkenes. Tetrahedron 37, 3229-3236 (1981).

44. Tamovsky, A. N., Alvarez, J. -L., Arkady, P., Sundstrom, V. \& Akesson, E. Photodissociation dynamics of diiodomethane in solution. Chem. Phys. Lett. 312, 121-130 (1999).

45. Chaudhury, M. K. \& Whitesides, G. M. How to make water run uphill. Science $\mathbf{2 5 6}$ 1539-1541 (1992).

Acknowledgements

We thank Isabel Casades (University of Edinburgh) for preliminary studies on fluoroalkane molecular shuttle systems and Bert de Boer and Sense Jan van der Molen (Materials Science Centre, University of Groningen) for providing heptadecafluorodecanethiol and the Xenon ultraviolet-lamp used in the transport studies. The Secretaría de Estado de Educación y Universidades and Fondo Social Europeo are acknowledged for a Postdoctoral Fellowship to J.B. This work was funded by the Engineering and Physical Sciences Research Council (UK) and as part of the EU research training network EMMMA and the Future and Emerging Technologies project MechMol.

Correspondence and requests for materials should be addressed to D.A.L., P.R. or F.Z

Supplementary Information accompanies this paper on www.nature.com/naturematerials.

Competing financial interests

The authors declare that they have no competing financial interests. 